\title{
Study of hydrophobin-type proteins from Funalia trogii
}

\author{
Artem Khludin ${ }^{1,}$, Boris Kolesnikov ${ }^{1}$, Nikita Khrapatov ${ }^{1}$, and Mark Shamtsyan ${ }^{1}$ \\ ${ }^{1}$ St. Petersburg State Institute of Technology (Technical University), 190013, Moskovsky prospect, \\ 26, St. Petersburg, Russia
}

\begin{abstract}
Hydrophobins are low-molecular surface-active proteins of fungi with high surface activity and the ability to self-assemble at the interface. The unusual properties of hydrophobins open up possibilities for their application in various fields, including medicine and the food industry. The wide range of possible applications of hydrophobins makes it important to develop and improve technology for their isolation and purification. The aim of the study was to select methods for the extraction of hydrophobin-type proteins and to study the ability of the obtained extracts to modify the solid surface. The source of hydrophobins in this study was the biomass of the fungus Funalia trogii. Methods for the isolation of hydrophobin-type proteins were developed, including purification of the extract from ballast proteins, followed by the destruction of agglomerates of hydrophobin-type proteins using acids in high concentrations. The surface activity and the ability to modify the surface of the obtained proteins were evaluated. As a result, we obtained extracts containing hydrophobin-type proteins with high surface activity. Funalia trogii extracts are capable of changing the hydrophobicity of the surface and can be used in various industries.
\end{abstract}

\section{Introduction}

Mushrooms are a source of a large number of useful substances: antibiotics, organic acids, carotenoids, enzymes, etc [1]. But the compounds contained in mushrooms can have not only high biological, but also surface activity. An interesting example of such compounds are structural proteins of fungi - hydrophobins. These proteins were discovered in 1986 while searching for genes expressed during the formation of aerial mycelium in the Schizophyllum commune [2]. Hydrophobins are a class of low molecular weight structural proteins consisting of about 100 amino acid residues and found exclusively in filamentous fungi. Hydrophobins contain 8 cysteine residues, which allows them to form 4 intramolecular disulfide bridges (Cys1-Cys6, Cys2-Cys5, Cys3-Cys4, Cys7-Cys8) [3]. Hydrophobins with high surface activity are capable of self-assembly into hydrophilic or hydrophobic amphipathic monolayers at the interface between the hydrophobic and hydrophilic phases, as well as on various surfaces [4]. As a result of the formation of such structures, the surface character changes from hydrophilic to hydrophobic (and vice versa).

\footnotetext{
${ }^{*}$ Corresponding author: xludin.ar@yandex.ru
} 
Based on the location of hydrophobic and hydrophilic residues, the type of amphipathic layer formed, its solubility, and the distribution of cysteine, hydrophobins are divided into two classes - class I and class II [5]. It was shown that, along with class I and II hydrophobins, there may be so-called intermediate forms of hydrophobins $[6,7]$.

Class I hydrophobins are of particular interest for use in various industries. Agglomerates formed by class I hydrophobins are highly resistant to mechanical and chemical influences, are soluble only in highly concentrated acids (for example, trifluoroacetic or formic), due to which they can form stable coatings on various surfaces [8].

The combination of the above properties opens up wide possibilities of using class I hydrophobin coatings to prevent the formation of biofilms on the surface of devices in the food and medical industry. This can reduce the likelihood of contamination and damage to the final product and the disabling of devices, as well as reduce the costs of enterprises for the systematic cleaning and disinfection of devices. The use of coatings based on class I hydrophobins in medicine will prevent biofouling of medical devices such as implants, catheters, scalpels and other medical instruments $[8,9]$. Due to the non-immunogenicity of hydrophobins, coatings based on them are able to increase the biocompatibility between the implant and the tissue, and avoid sepsis $[10,11]$. In addition, the coverage of scalpels with class I hydrophobins will significantly reduce tissue trauma due to a decrease in the friction force between the instrument and the patient's body tissues [12]. Hydrophobins can also be used to immobilize proteins on solid surfaces, which can be further used in biodetection, for example, for biosensors and microfluidic devices [13].

The wide range of applications of hydrophobins necessitates research to develop an optimal technology for their isolation and purification, which will be economically feasible and simple in hardware design.

The aim of the study was to select methods for the extraction of hydrophobin-type proteins and to study the ability of the obtained extracts to modify the solid surface.

\section{Materials and methods}

\subsection{Submerge cultivation of Funalia trogii}

The source of hydrophobins in this study was the biomass of the fungus Funalia trogii. The cultivation of the fungus was carried out by the method of submerged cultivation. As a nutrient medium the semisynthetic glucose-peptone medium was used (g/1): glucose 10,0 , peptone - 2,5, $\mathrm{NaCl}-0,5, \mathrm{KH}_{2} \mathrm{PO}_{4}-0,6, \mathrm{~K}_{2} \mathrm{HPO}_{4}-0,4, \mathrm{MgSO}_{4}-0,5$, yeast extract 2,0 . Submerged cultivation was carried out in $750 \mathrm{ml}$ Erlenmeyer flasks with $100 \mathrm{ml}$ of nutrient medium at a temperature of $28-30{ }^{\circ} \mathrm{C}$ on a rotary shaker. At the end of cultivation, the biomass of the fungus was separated from the native solution by filtration.

Isolation of hydrophobins from fungal biomass was carried out by the extraction method. Funalia trogii belongs to basidiomycetes that contain only class I hydrophobins. Due to the fact that hydrophobins of this class form extremely persistent agglomerates, trifluoroacetic and formic acids were used in the extraction process.

\subsection{Ballast protein removal}

At the initial stage, the fungus biomass was purified from ballast proteins. The purification method is based on the fact that agglomerates of class I hydrophobins, unlike other proteins, are insoluble in a hot SDS solution [8]. Fungus cells were destroyed by successive freezing and thawing. Then the biomass was dried to constant weight at a temperature 60 
${ }^{\circ} \mathrm{C}$. Extraction of ballast proteins was carried out by keeping the dried biomass in $0.1 \mathrm{M}$ Tris- $\mathrm{HCl}$ buffer $(\mathrm{pH}=10)$ with the addition of $2 \%$ SDS for 2 hours at a temperature of 100 ${ }^{\circ} \mathrm{C}$. Samples of the extract were taken every 20 minutes to determine the amount of extracted proteins. The protein content in the sample was measured by the Lowry method. After two hours, the biomass was separated from the extract by filtration. The biomass was washed from the buffer solution residues with fifty volumes of distilled water and dried to constant weight at a temperature of $60^{\circ} \mathrm{C}$.

\subsection{Isolation of hydrophobins using formic acid}

The biomass purified from ballast proteins was kept in a $92 \%$ formic acid solution at a temperature of $4{ }^{\circ} \mathrm{C}$ for 2 hours. Then the biomass was separated from the extract by centrifugation for 15 minutes at $4500 \mathrm{~g}$ and a temperature of $4{ }^{\circ} \mathrm{C}$ Agglomerates of hydrophobin-type proteins contained in the supernatant were destroyed by a double volume of performic acid. The destruction was carried out for 4 hours in an ice bath [14]. The resulting extract was diluted with water in a 1: 2 ratio and neutralized with $10 \mathrm{M} \mathrm{NaOH}$ in an ice bath with constant stirring. The amount of protein in the extract was measured by the Lowry method.

\subsection{Isolation of hydrophobins using trifluoroacetic acid}

The biomass purified from ballast proteins was kept in $99 \%$ trifluoroacetic acid at a temperature of $4{ }^{\circ} \mathrm{C}$ for 2 hours [15]. Then the biomass was separated from the extract by centrifugation for 15 minutes at $4500 \mathrm{~g}$ at a temperature of $4{ }^{\circ} \mathrm{C}$. Trifluoroacetic acid was evaporated at $75^{\circ} \mathrm{C}$. The obtained protein was dissolved in distilled water and the protein concentration was measured by the Lowry method.

\subsection{Measurement of the contact angle of wetting a surface modified by hydrophobins}

To assess the ability of solutions containing hydrophobin-type proteins to modify surfaces by changing their nature, the effect of these solutions on changing the contact angle of surface wetting was studied. A fluoroplastic plate was covered with a solution of hydrophobins of various concentrations, dried in the desiccator at a temperature of $50{ }^{\circ} \mathrm{C}$, after which the contact angle of the modified plate wetting with distilled water was measured. The measurements were carried out using a KM-6 cathetometer. The value of the contact angle of wetting was determined by the formula:

$$
\cos \theta=\frac{\left(\frac{d}{2}\right)^{2}-h^{2}}{\left(\frac{d}{2}\right)^{2}+h^{2}}
$$

where $\cos \theta$ - the cosine of the contact angle;

$d$ - diameter of the droplet base, $\mathrm{mm}$;

$h$-drop height, $\mathrm{mm}$. 


\section{Results and discussion}

\subsection{Purification of F.trogii biomass from ballast proteins}

The ballast proteins were extracted with $0.1 \mathrm{M}$ Tris- $\mathrm{HCl}$ buffer $(\mathrm{pH}=10)$ with the addition of $2 \%$ SDS for 2 hours. Samples were taken every 20 minutes to determine the amount of extracted proteins. The dynamics of changes in the content of proteins in solution is shown in Figure 1.

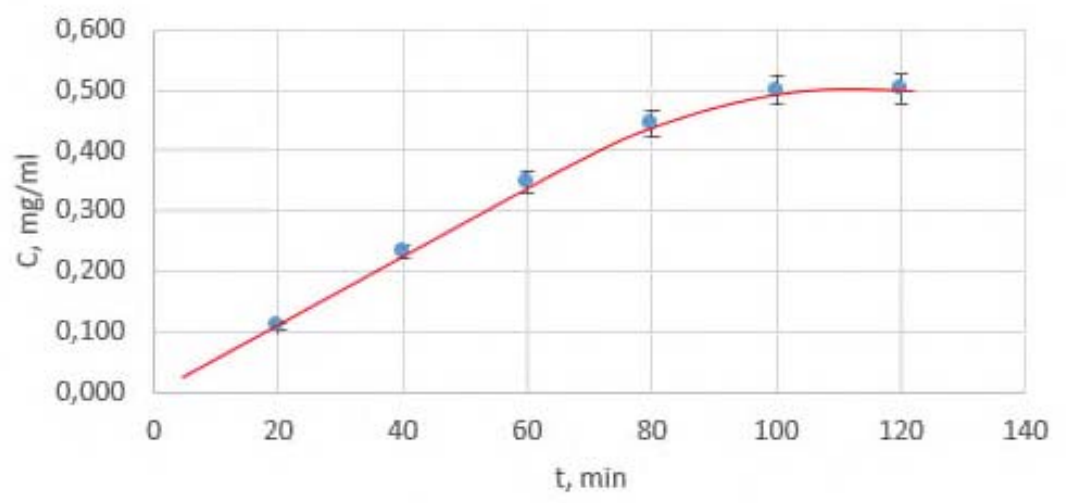

Fig. 1. Dynamics of changes in the content of proteins in solution during extraction.

It can be seen from the above results that the optimal time for purification of the biomass of the fungus F.trogii from non-hydrophobin-type proteins is 100 minutes, since during further boiling, proteins from the biomass do not pass into solution.

\subsection{Extraction of hydrophobin-type proteins}

The destruction of agglomerates of hydrophobin-type proteins and their subsequent extraction was carried out using formic and trifluoroacetic acids. At the end of the extraction, the yield of hydrophobin-type proteins was calculated for both extraction methods. The results are shown in Table 1.

Table 1. Comparison of methods for the extraction of hydrophobin-type proteins from the biomass of F.trogii.

\begin{tabular}{|l|c|}
\hline \multicolumn{1}{|c|}{ Extractant } & $\begin{array}{c}\text { Yield of hydrophobin-type } \\
\text { proteins, } \mathrm{mg} / \mathrm{g}\end{array}$ \\
\hline Formic acid & $4,32 \pm 0,19$ \\
\hline Trifluoroacetic acid & $1,03 \pm 0,07$ \\
\hline
\end{tabular}

Based on the above data, it can be concluded that the extraction of hydrophobin-type proteins using formic acid is more efficient than with trifluoroacetic acid. This may be due to the fact that trifluoroacetic acid is capable of degrading proteins when heated.

\subsection{Accumulation of biomass and hydrophobin-type proteins during submerged cultivation of $F$. trogii}

To determine the optimal cultivation time, we studied the dynamics of the accumulation of biomass and hydrophobin-type proteins during submerged cultivation of the fungus F.trogii. The results are shown in Figure 2. 


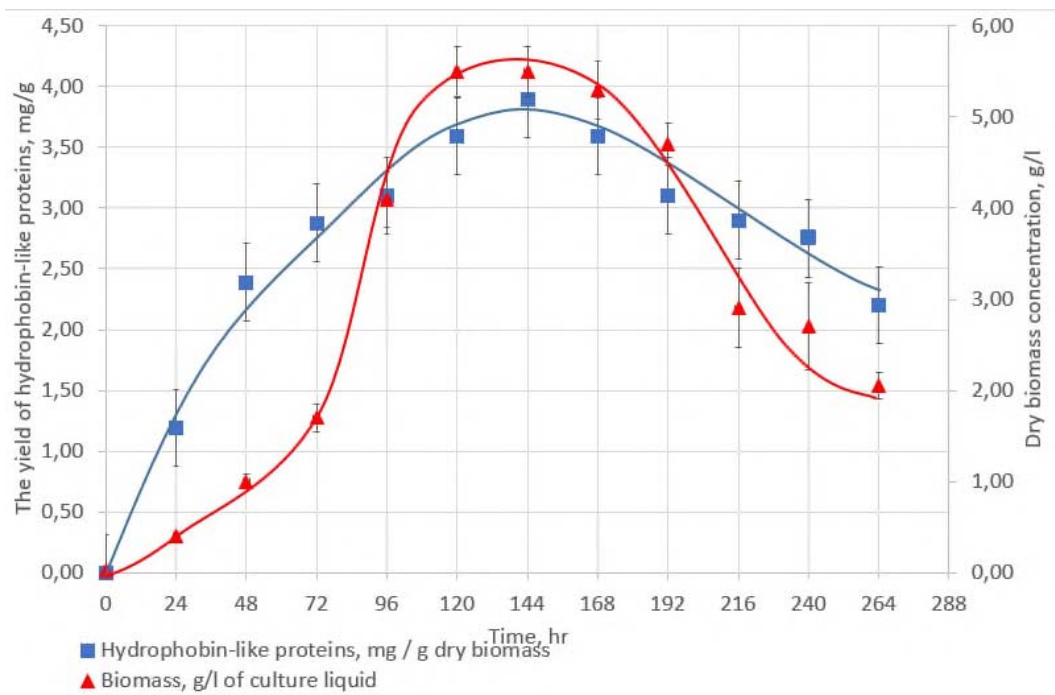

Fig. 2. Dynamics of the accumulation of biomass and hydrophobin-type proteins during submerged cultivation of the fungus F.trogii.

The results show that the maximum accumulation of biomass falls on 144 hours from the beginning of cultivation. The maximum yield of hydrophobin-type proteins also falls on 140-145 hours from the beginning of cultivation. Based on these facts, we can conclude that the optimal time for submerged cultivation is 144 hours, since at this time the highest yield of hydrophobin-type proteins per unit of dry biomass is observed, the increase of which is also maximum. The conclusions are confirmed by the graph shown in Figure 3.

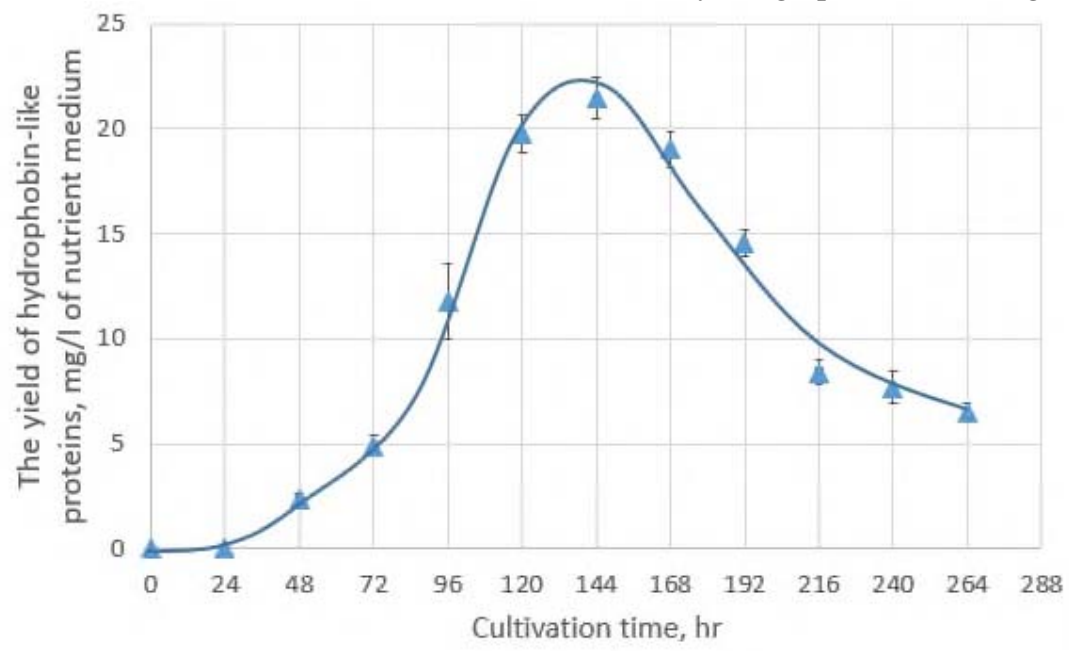

Fig. 3. Yield of hydrophobin-type proteins, $\mathrm{mg} / 1$ of culture liquid.

\subsection{Study of the surface activity of solutions of hydrophobin-type proteins}

The surface activity of hydrophobin-type proteins was studied, as well as their ability to modify the surface. 
For this purpose, the contact angle of surface wetting was measured with solutions containing hydrophobin-type proteins in different concentrations and with SDS solution. The results are shown in Figure 4.

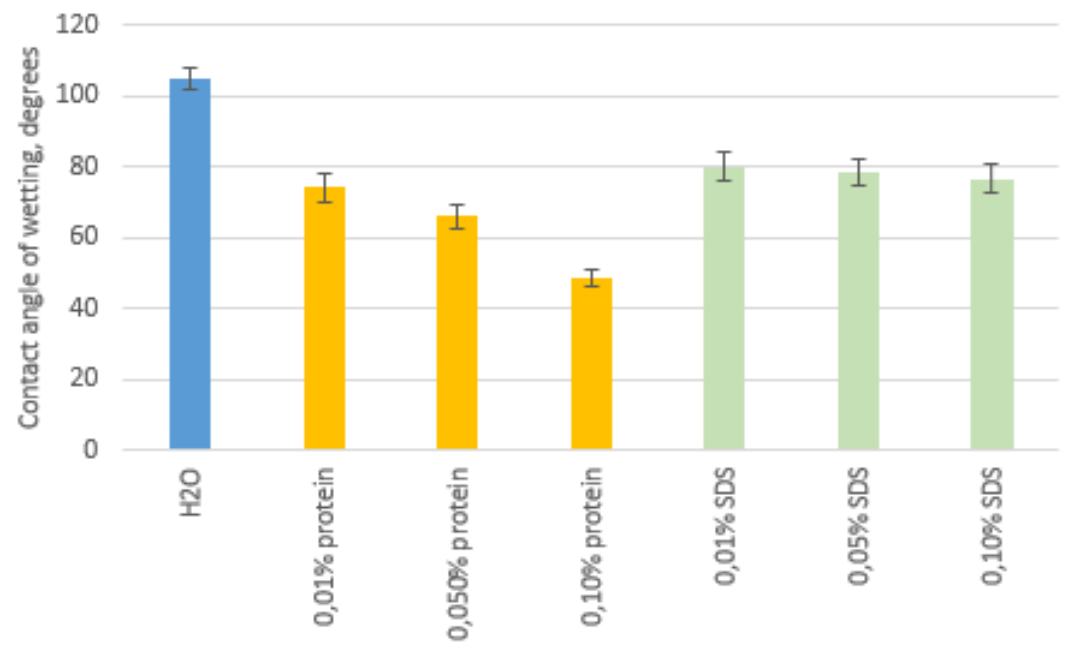

Fig. 4. Contact angle of surface wetting with solutions of hydrophobin-type proteins.

It can be seen from the results that proteins isolated from the biomass of F.trogii have high surface activity comparable to that of SDS.

An experiment was carried out to modify the fluoroplastic surface with solutions of hydrophobin-type proteins of different concentrations. Solutions of hydrophobin-type proteins with concentrations of $0.01 \%, 0.05 \%, 0.1 \%$, and $1 \%$ were applied to a fluoroplastic surface and dried in an air stream at room temperature. Then, $10 \mathrm{mkl}$ of distilled water was applied to them and the contact angle was measured. The results are shown in Table 2.

Table 2. Contact angle of a fluoroplastic surface treated with a solutions of hydrophobin-type proteins.

\begin{tabular}{|c|c|}
\hline $\begin{array}{c}\text { Protein } \\
\text { concentration }\end{array}$ & Contact angle of wetting, degree \\
\hline $0,01 \%$ & $63,0 \pm 3,7$ \\
\hline $0,050 \%$ & $34,4 \pm 2,1$ \\
\hline $0,10 \%$ & $30,4 \pm 1,7$ \\
\hline $1,0 \%$ & $26,2 \pm 1,6$ \\
\hline
\end{tabular}

A significant change in the contact angle indicates a change in the nature of the surface from hydrophilic to hydrophobic. Due to the fact that surface modification by hydrophobins occurs due to their self-assembly into agglomerates at the interface, the dynamics of the formation of agglomerates of hydrophobin-type proteins was studied.

$0.1 \%$ solution of hydrophobin-type proteins in trifluoroacetic acid was applied to the fluoroplastic surface. The plate was dried in an air stream at room temperature. After that $10 \mathrm{mkl}$ of distilled water was applied to a fluoroplastic plate coated with hydrophobin-type proteins, and the contact angle was measured with an interval of 20 seconds. The measurement results are shown in Figure 5. 


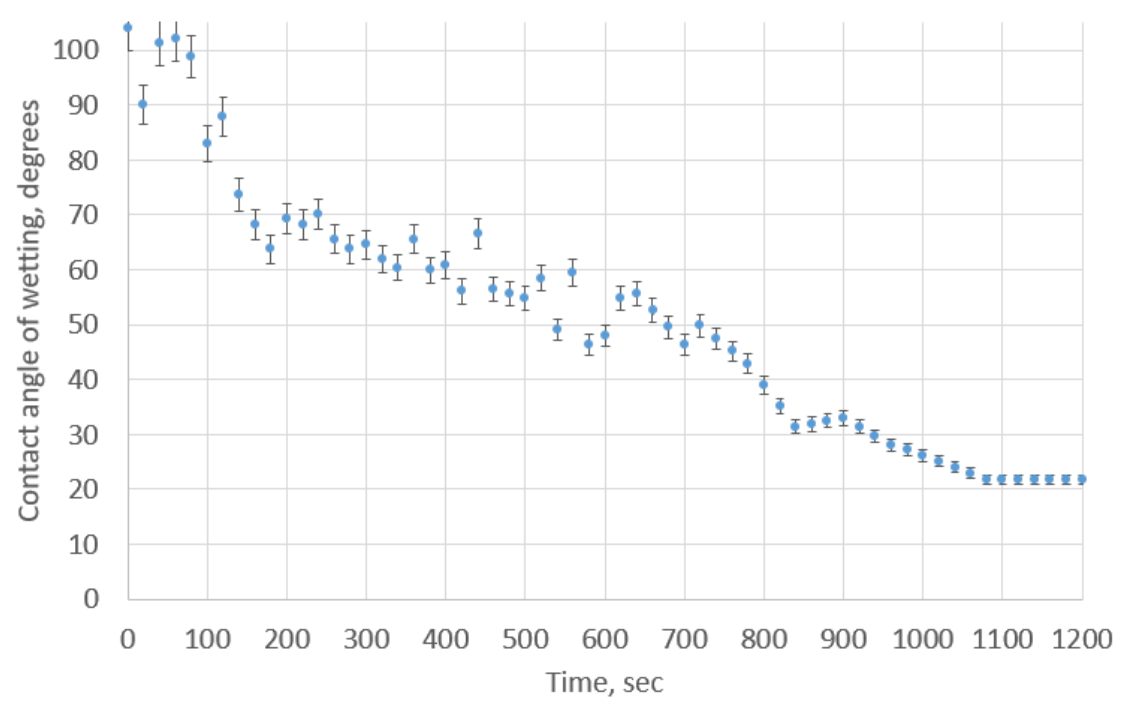

Fig. 5. Dynamics of modification of the fluoroplastic surface by hydrophobin-type proteins.

From the graph, it can be assumed that an insignificant change in the contact angle at the beginning of the experiment is associated with the transition of hydrophobin-type proteins on the surface of the plate into a dissolved form. A further sharp decrease in the contact angle can be explained by an increase in the concentration of hydrophobin-type proteins at the air / water interface, which causes a decrease in the surface tension of water until the air / water interface becomes saturated. The subsequent less intense decrease in the contact angle is probably associated with the formation of agglomerates at the water / solid interface (surface modification). As follows from the figure, the change in the contact angle of wetting, and, consequently, the modification of the surface, ends approximately 1100 seconds after the beginning of the experiment.

\section{Conclusion}

As a result of our studies, we obtained extracts from the culture of the fungus $F$. trogii containing hydrophobin-type proteins. Techniques for the isolation of hydrophobin-like proteins were developed. The extraction of hydrophobin-type proteins using formic acid is more efficient than with trifluoroacetic acid. The yield of hydrophobins was 4,32 $\pm 0,19 \mathrm{mg}$ / $g$ of biomass. The resulting extracts showed a high surface activity comparable to that of SDS, as well as the ability to modify hydrophobic surfaces. Hydrophobin-type proteins from $F$. trogii can be widely used in medicine. Further studies will be devoted to the optimization of methods for the isolation of hydrophobin-type proteins from $F$. trogii and the study of the possibility of their practical application.

\section{References}

1. M. Shamtsyan, Potential to develop functional food products from mushroom bioactive compounds, Journal of Hygienic Engineering and Design 15, 51-59 (2016)

2. G.H. Mulder, G.H. Wessels, Molecular cloning of RNAs differentially expressed in monokaryons and dikaryons of Schizophyllum commune in relation to fruiting, Exp. Myc. 10 (1986) https://doi.org/10.1016/0147-5975(86)90006-X 
3. A.H.Y. Kwan, R.D. Winefield, M. Sunde, J.M. Matthews, R.G. Haverkamp, M.D. Templeton, J.P. Mackay, Structural basis for rodlet assembly in fungal hydrophobins, Proc. Natl. Acad. Sci. USA. 103 (2006) https://doi.org/10.1073/pnas.0505704103

4. H.J. Hektor, K. Scholtmeijer, Hydrophobins: proteins with potential, Cur. Op. in Biotech. 16, 7 (2005) https://doi.org/10.1016/j.copbio.2005.05.004

5. J.G. Wessels, Hydrophobins: proteins that change the nature of the fungal surface, Adv. Microb. Physiol. 38 (1997) https://doi.org/10.1016/S0065-2911(08)60154-X

6. B.G. Jensen, M.R. Andersen, M.H. Pedersen, J. Frisvad, I. Søndergaard, Hydrophobins from Aspergillus species cannot be clearly divided into two classes, BMC Res. Notes. 3 (2010) https://doi.org/10.1186/1756-0500-3-344

7. K.A. Littlejohna, P. Hooleyb, P.W. Cox, Bioinformatics predicts diverse Aspergillus hydrophobins with novel properties, F. Hydrocol. 27 (2012)

8. M. Artini, P. Cicatiello, A. Ricciardelli, R. Papa, L. Selan, P. Dardano, M. Tilotta, G. Vrenna, M.L. Tutino, P. Giardina, E. Parrilli, Hydrophobin coating prevents Staphylococcus epidermidis biofilm formation on different surfaces, Biof.ouling. 33, 7 (2017) https://doi.org/10.1080/08927014.2017.1338690

9. V. Lo, J.I-Chun Lai, M. Sunde, Fungal Hydrophobins and Their Self-Assembly into Functional Nanomaterials, Biol. and Bio-insp. Nanomat. 1174 (2019) https://doi.org/10.1007/978-981-13-9791-2_5

10. M.I. Janssen, M.B.B. van Leeuwen, Th.G. van Kooten, J. de Vries, L. Dijkhiuzen, H. Wosten, Promotion of fibroblast activity by coating with hydrophobins in the $b$-sheet end state, Biomat. 25 (2004, https://doi.org/10.1016/j.biomaterials.2003.09.060

11. K. Scholtmeijer, M.I. Janssen, B. Gerssen, M.L. de Vocht, B.M. van Leeuwen, Th.G. van Kooten, H.A.B. Wösten, J.G.H. Wessels,Surface modifications created by using engineered hydrophobins, Appl. Environ. Microbiol. 68 (2002) https://doi.org/10.1128/AEM.68.3.1367-1373.2002

12. R. Misra, J. Li, G.C. Cannon, S. E. Morgan, Nanoscale reduction in surface friction of polymer surfaces modified with Sc3 hydrophobin from Schizophyllum commune, Biomacromol. 7 (2006) https://doi.org/10.1021/bm050983y

13. M. Torkkeli, R. Serimaa, O. Ikkala, Aggregation and Self-Assembly of Hydrophobins from Trichoderma reesei: Low-Resolution Structural Models, Bioph. J. 83, 4 (2002) https://doi.org/10.1016/S0006-3495(02)73984-2

14. J. Wessels, O. de Vries, S.A. Asgeirsdottir, F. Schuren, Hydrophobin Genes lnvolved in Formation of Aerial Hyphae and Fruit Bodies in Schizophyllum, The Plant Cell. 3 (1991) https://doi.org/10.1105/tpc.3.8.793

15. O.M.H. de Vries, M.P. Fekkes, H.A.B. Wosten, J.G. Wessels, Insoluble hydrophobin complexes in the walls of Schizophyllum commune and other filamentous fungi, Arch. Microbiol. 159 (1993) 